\title{
A CLINICAL EVALUATION OF THE RYGG-KYVSGAARD III AND THE MARK III PUMP OXYGENATORS
}

BY

\author{
E. ARNFRED, INGE H. RYGG, THORKILD FREDERIKSEN, H. C. ENGELL, \\ THUE POULSEN, AND J. ROSEN \\ From the Departments of Surgery $D$ and $R$, the Department of Anaesthesia, and the Central \\ Laboratory, Rigshospitalet, University of Copenhagen
}

(RECEIVED FOR PUBLICATION FEBRUARY 20, 1961)

In the Departments of Surgery $D$ and $R$ of the University Hospital of Copenhagen (Rigshospitalet) two pump oxygenators of different types, namely, the Rygg-Kyvsgaard III bubble oxygenator and the mark III screen oxygenator, have during the last two years been used in two parallel series of perfusions. An opportunity has thus been provided for comparing the efficacies of the two oxygenators. Since only a few such investigations have been made previously (Gerbode, Osborn, Melrose, Perkins, Norman, and Baer, 1958), and there has been some doubt about the applicability of the bubble oxygenators (Maloney, Longmire, Schmutzer, Marable, Raschke, Watanabe, Lobpreis, and Arzouman, 1958), we have thought it of interest to publish our results. The work comprises only human perfusions, and the series were concluded in September, 1960 (Engell, Rygg, Arnfred, Frederiksen, and Thue Poulsen, 1961).

\section{Description of the Pump Oxygenators}

The two pieces of apparatus are a bubble oxygenator of the type Rygg-Kyvsgaard III constructed at the Department $\mathbf{R}$ of the University Hospital of Copenhagen, and a stationary screen oxygenator of the type mark III developed by Gaertner and Kay according to Gibbon's principle (Gibbon, 1953).

RygG-Kyvsgand III Pump Oxygenator.-This (Fig. 1a and b) is of a construction which permits the greater part of the material getting into contact with the blood to be discarded after use. A plastic bag containing both an oxygenating column and a reservoir is used as oxygenator. The blood flows by gravity from the caval veins to the oxygenating column, to which also the blood from the suctions is led, and here oxygen is added to the blood at a ratio of about one and a half times the blood flow according to the size of the patient. Afterwards the blood is defoamed in a silicone-coated sponge and flows to the arterial reservoir through two filters.
Only one pump is used in the apparatus, namely, an eccentric roller pump set for occlusion. This pump carries the arterialized blood from the bag through a filter with a bubble trap to the patient. The oxygenator is suspended in a thermostat box on a pair of scales. As with the oxygenator all tubing is disposable (Rygg and Kyvsgaard, 1957; Gammelgaard, Husfeldt, and Therkelsen, 1957 ; Rygg, Engell, and Kyvsgaard, 1956; Rygg, 1958; Rygg and Kyvsgaard, 1958 ; Therkelsen, Thue Poulsen, Rosen, and Rygg, 1961).

Mark III Pump Oxygenator.-This model (Fig. 2a and $b$ ) includes a screen oxygenator with 16 screens. A recirculation pump of the DeBakey type is used to maintain the blood flow over the screens. The blood flows by gravity from the caval veins to a reservoir, where, together with the blood from the suctions, it is mixed with the recirculation blood in the apparatus. The arterial flow is pumped from the bottom of the oxygenator (generally via a heat exchanger) by an occlusive DeBakey pump through a filter with a bubble trap back to the patient. The oxygenator and the other chambers in the apparatus are made from lucite $\mathbf{R}$ and highly polished stainless steel. Connexions are made either from Tygon $\mathbf{R}$ or from stainless steel, and the tubing is made from Tygon R.

Sterilization.-In the Rygg-Kyvsgaard III apparatus the tubing and the steel parts are sterilized by boiling or by autoclaving. The oxygenator is sterilized by irradiation at the Danish Atomic Energy Commission, Research Establishment, Risø. The mark III apparatus is sterilized in its entirety by being kept with a $1.25 \%$ solution of Warexin $R$ inside it (Christensen and Helweg-Mikkelsen, 1959).

Technical Accident.-In the Rygg-Kyvsgaard III series no technical accidents influencing the course of the perfusion were reported.

During the tenth perfusion with the mark III apparatus, in which a case of Steno-Fallot's disease was being operated on, an increasing leakage in the tube in the recirculation pump occurred after 26 minutes' perfusion. During the indispensable replace- 
TABLE I

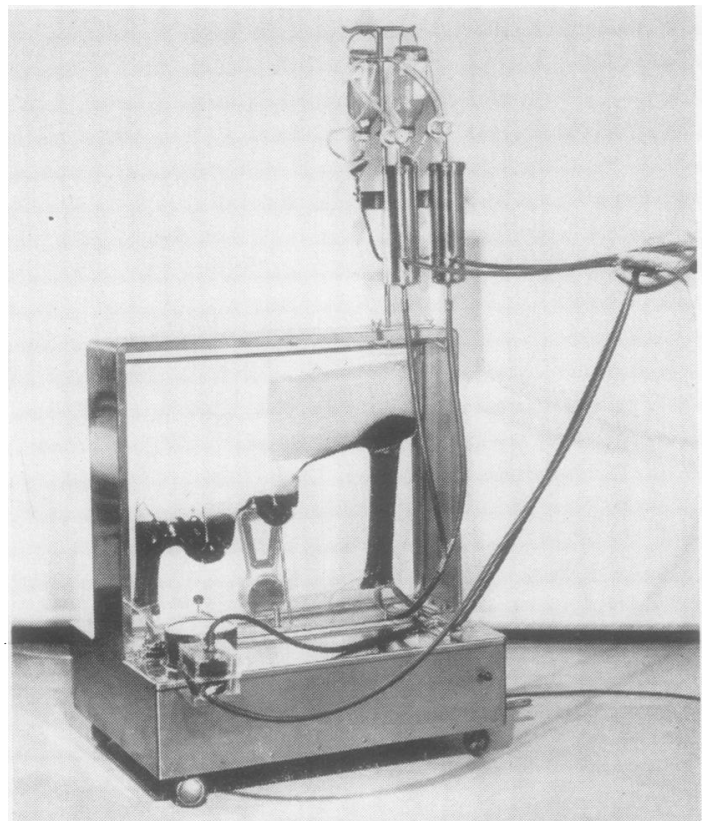

FIG. 1a.-The Rygg-Kyvsgaard III pump oxygenator.

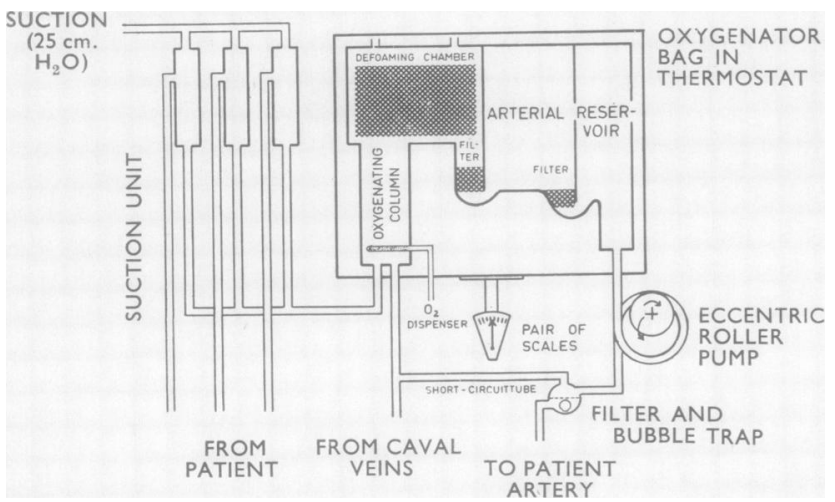

FIG. 1b.-Diagram of the Rygg-Kyvsgaard III pump oxygenator.

ment of the tube some blood was lost, and as a heavy haemorrhage occurred simultaneously in the operative field with a consequent reduction of the venous backflow to the apparatus, the oxygenator was emptied of blood, and air was pumped into the arterial system.

\section{The Material}

The total number of patients on whom, within the scope of the present investigation, operations were performed using the two models was 79,48 in the mark III series and 31 in the Rygg-Kyvsgaard III series. The distribution for age and sex is shown in Table I, from which it appears that in the mark III series the ages of the patients ranged from 5 to 45 years, the greater part of the patients falling within

AGE AND SEX DISTRIBUTION IN 79 CASES OF EXTRAAGE KYVSGAARD III PUMP OXYGENATORS

\begin{tabular}{c|ccc|c|cc}
\hline $\begin{array}{c}\text { Age } \\
\text { Group }\end{array}$ & \multicolumn{3}{c|}{ Mark III } & \multicolumn{3}{c}{ Rygg III } \\
(Years) & Male & Female & Total & Male & Female & Total \\
\hline $0-2$ & & & & & 1 & 1 \\
$3-5$ & & 1 & 1 & & 2 & 2 \\
$6-10$ & 4 & 5 & 9 & 6 & 3 & 9 \\
$11-15$ & 7 & 7 & 14 & & 2 & 2 \\
$16-20$ & 1 & 4 & 5 & 3 & 2 & 5 \\
$21-25$ & 3 & 5 & 8 & 2 & 1 & 3 \\
$26-30$ & & 3 & 3 & & 2 & 2 \\
$31-35$ & & 1 & 1 & & 2 & 2 \\
$36-40$ & 2 & 1 & 3 & & 3 & 3 \\
$41-45$ & 1 & 3 & 4 & & 1 & 1 \\
$46-50$ & & & & & 1 & 1 \\
$51-55$ & & & & & 20 & 31 \\
\hline Total & 18 & 30 & 48 & 11 & 20 \\
\hline
\end{tabular}

the age group 6 to 25 years, whereas the patients in the Rygg-Kyvsgaard III series ranged from $1 \frac{1}{2}$ to 54 years old, here, too, the majority being between 6 and 25 years of age. In both series most of the patients were women and girls, namely, 30 out of 48 cases and 20 out of 31 cases respectively.

In the mark III series the weights of the patients ranged from 16.7 to $75.1 \mathrm{~kg}$., and the body surfaces ranged from 0.69 to 2.00 sq.m. The corresponding figures for the Rygg-Kyvsgaard III series were 8.4 to $70.5 \mathrm{~kg}$. and 0.43 to 1.85 sq.m. respectively.

The diagnoses are shown in Table II. The cases have been divided into two main groups, namely, (1) simple atrial septal defects, i.e., cases in which the atrial septal defect was not attended by malformations in the heart other than anomalous pulmonary veins, and in which there have been no heavy haemorrhages

TABLE II

DIAGNOSES IN 79 CASES OF EXTRACORPOREAL CIRCULATION

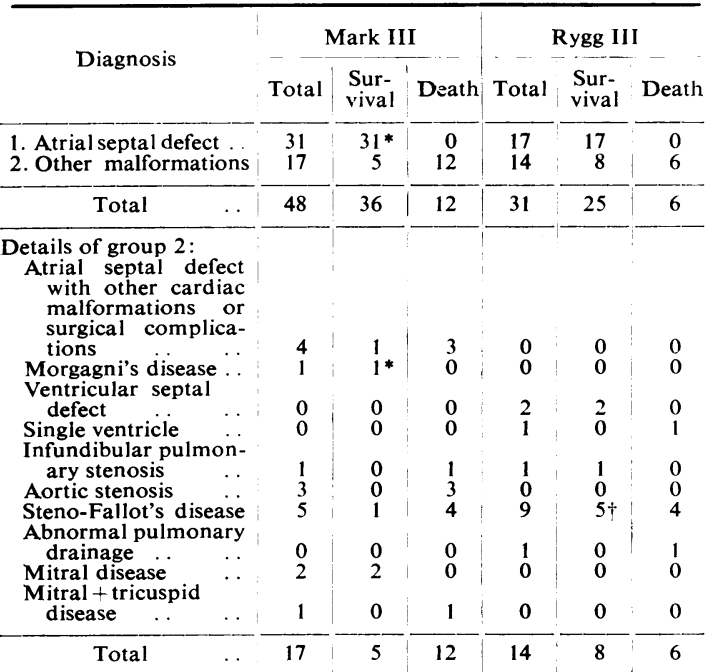

* One patient died after discharge. † One patient died 42 days post-operatively. 
or other surgical complications during the operations, thus providing a satisfactory basis for a comparison of the perfusions, and (2) more complicated malformations, in which the haemodynamic conditions and also the more complicated surgical procedures do not to the same degree as in group 1 permit of a direct comparison. This group includes such cases of atrial septal defect where there have also been other malformations of the heart, or where there have been

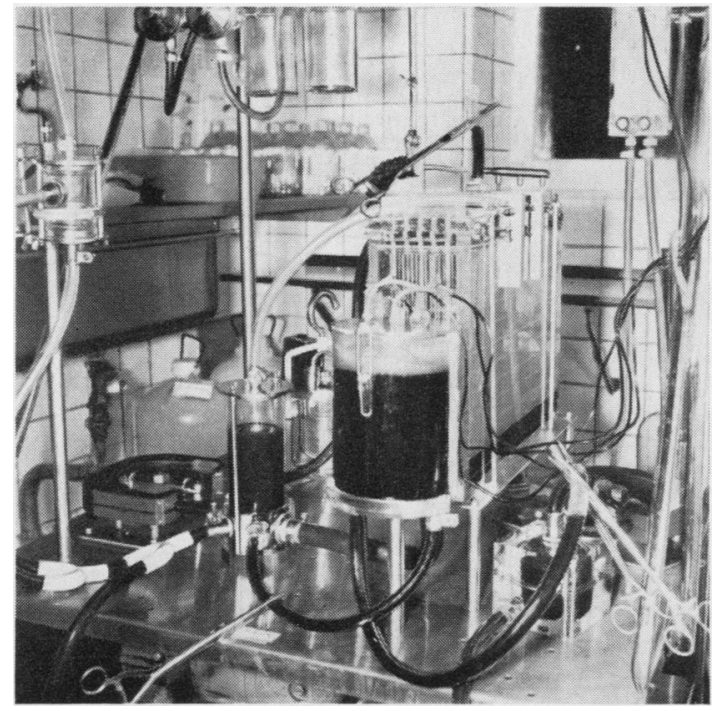

FIG. 2a.-The mark III pump oxygenator.

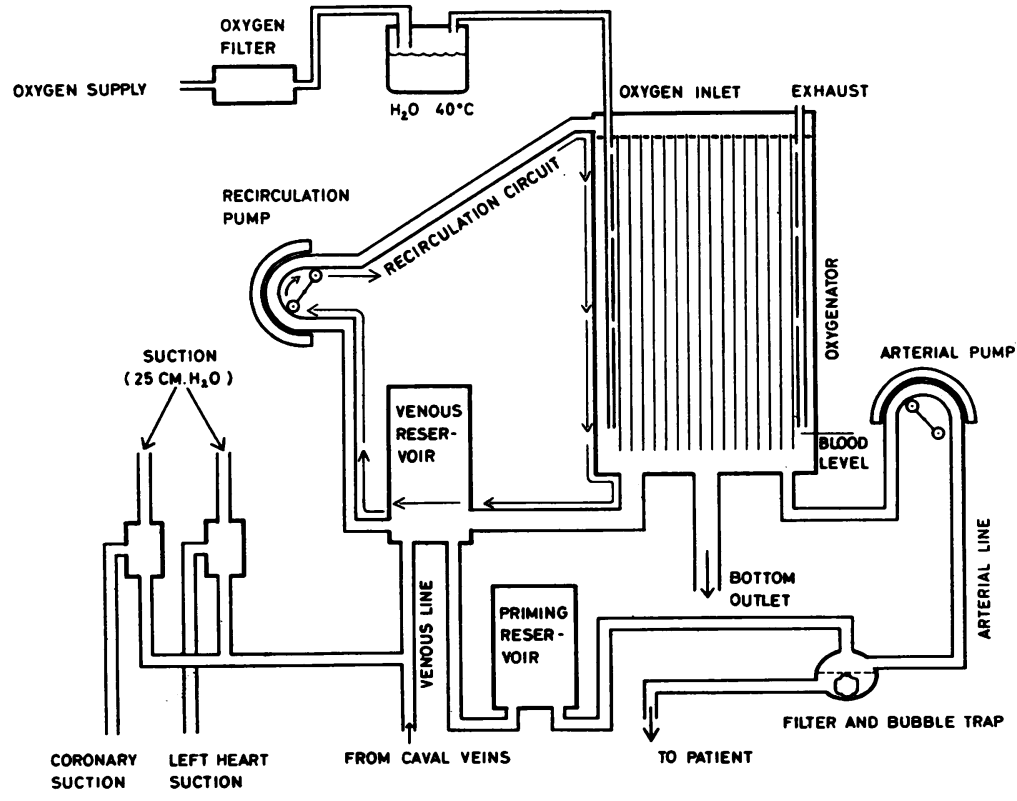

FIG. 2b.-Diagram of the mark III pump oxygenator. surgical complications to such an extent that the cases have been unable to meet the requirements for inclusion in group 1.

A specification for group 2 is given in the lower section of Table II. Under the heading "Death" are registered such cases in which death was closely connected with the operation or during the postoperative period proper, whereas patients who actually recovered from the operation and the extracorporeal circulation but who afterwards died from heart disease or as a result of the operation have been mentioned in a footnote.

Table III contains a survey of the causes of death. It appears that, apart from the instance of massive air embolism mentioned above, no patients within the two series died as a result of the perfusion. In the Rygg-Kyvsgaard III series particularly deaths or complications which might be assigned to air embolic processes have not been found.

A survey of the clinical course of most of the cases of atrial septal defect in the mark III material has been given elsewhere (Husfeldt, Engell, and Arnfred, 1961).

\section{Perfusion Data}

To be able to make a satisfactory comparison of the perfusions performed by the two models, it is necessary that the perfusion technique in the two groups of cases be uniform, and that the external circumstances of the perfusions be as homogenous as possible, or that possible divergencies are of such a nature that corrections can be made for comparison.

It appears from Table IV that a comparison of the perfusions is possible with regard to caval occlusion time, arterial pressure, and blood flow. The average caval occlusion time was in the mark III series 31 minutes and in the Rygg-Kyvsgaard III series 29 minutes. Caval occlusion time for the two groups of patients was 18 minutes for group 1,30 minutes for surviving cases in group 2, and about one hour for fatal cases in group 2.

The arterial flow in the mark III series varied between 1.3 and 5.0 litres/sq.m./min. with a mean of 2.7, whereas the corresponding values in the Rygg-Kyvsgaard III series varied between 2.0 and 3.1 litres/sq.m./min. with a mean of 2.6 .

The arterial pressure obtained during the perfusion is practically the same for the two series, and the range of distribution is of the same magnitude. A sudden drop in the arterial 
TABLE III

CAUSE OF DEATH IN 18 FATAL CASES

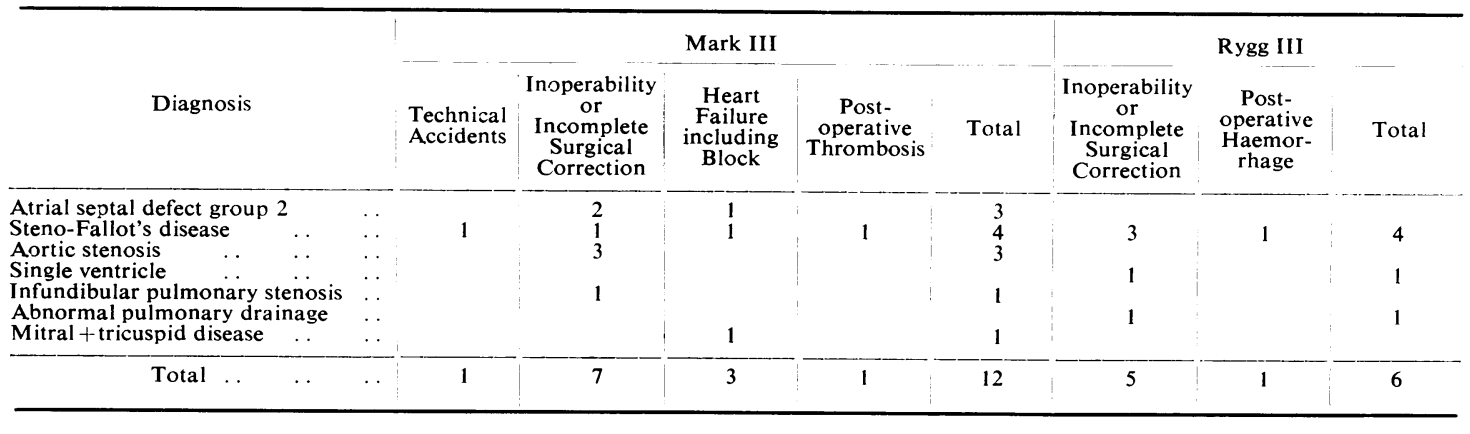

TABLE IV

TECHNICAL DATA FROM 79 PERFUSIONS

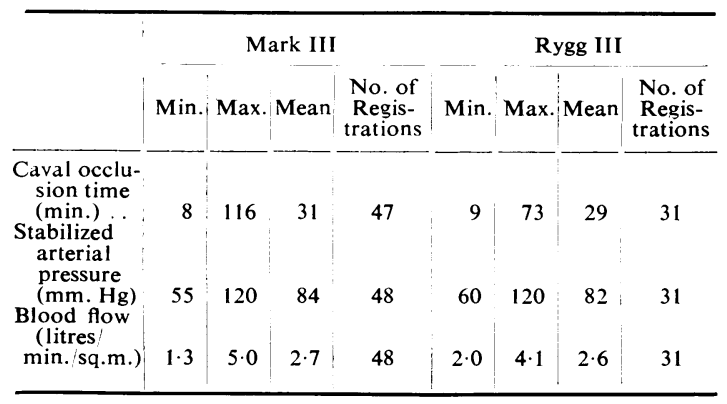

pressure occurred in the first minutes after caval occlusion in the mark III series, whereas a corresponding feature was not observed in the perfusions with the Rygg-Kyvsgaard III apparatus. Individual curves showing the arterial pressure during perfusions with the mark III apparatus are given in a previous publication (Husfeldt, Engell, Juhl, Rosen, Sand $\varnothing$ e, and Arnfred, 1959).

The priming volume of the Rygg-Kyvsgaard III pump oxygenator varies with the size of the oxygenator used between 1.5 and 3.0 litres, and the average volume in this series was 2.4 litres. The mark III pump oxygenator has, on the other hand, a fixed priming volume of 2.8 litres without and 3.5 litres with a heat exchanger.

\section{REgISTRATIONS}

Arterial and venous pressure was measured by means of Tybjoerg Hansen's manometer (Tybjoerg Hansen, 1949), and the temperature by means of thermocouples placed in the oesophagus and the rectum. Blood samples for determining the biochemical changes were drawn from the patient's arterial system and from the apparatus immediately before the perfusion, from the patient's arterial system and the venous line of the apparatus at the beginning and at the end of caval occlusion time, and from the patient's arterial system about 15 and about 60 minutes after the conclusion of the extracorporeal circulation.
Haemoglobin, arterial $p \mathrm{H}$, standard bicarbonate. and $\mathrm{pCO}_{2}$ were measured by Astrup's micro method (Andersen, Siggaard, Engel, Jørgensen, and Astrup, 1960). The oxygen saturation in the blood was measured by Kipp's haemoreflector. Moreover, serum sodium, serum potassium, serum chloride, and free haemoglobin in serum were determined, and, finally, leucocyte counts, including differential count, thrombocyte count, and total serum protein were made.

\section{Results}

OXYGEN UPTAKE.-For the investigation of the oxygen uptake by the patients during the perfusion, the oxygen saturation in the patient's arterial blood and in the mixed venous blood from the caval veins was determined. Fig. 3 is a scattergram of these values from both groups. Apart from a more pronounced dispersal of the values in the mark III series, no greater variance is found between the two materials.

The oxygen uptake of the individual patients in group 1 has been computed as an average of the oxygen uptake at the beginning and at the end of the caval occlusion time on the basis of the arteriovenous oxygen deficit, the amount of haemoglobin in the blood, and the arterial flow, no heed being paid to the physically bound quantity of oxygen at

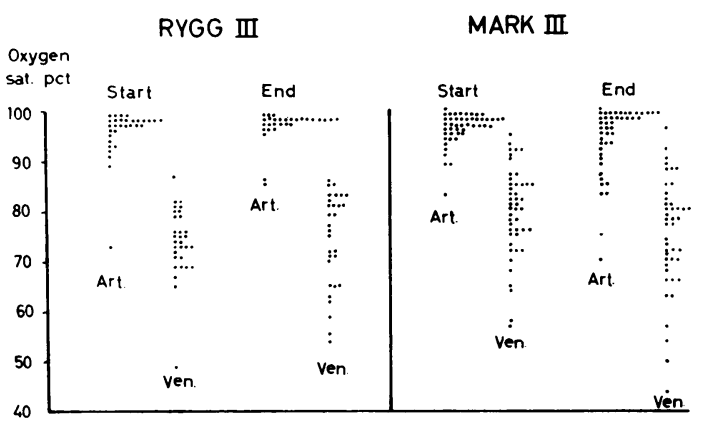

FIG. 3.-Scattergram showing arterial and venous oxygen saturation at the start and at the end of the caval occlusion time. 
this coarse comparison. Furthermore, the uptake established is not correct in so far as the amount of blood which is returned through the suctions does not lend itself to examination. However, in cases of simple atrial septal defect, which are the only ones in which this comparison has been made, this return is generally very small, for which reason the determinations have been considered sufficiently precise to render possible a comparison of the perfusions within this group.

The oxygen uptake in each individual case is expressed as a percentage of a calculated oxygen uptake for an individual of the age and sex of the patient surveyed, corrected to the actual temperature, reckoning $Q_{10}=2.5$ (Du Bois, 1921 ; Boothby and Sandiford, 1929; Lewis, Kinsman, and Iliff,

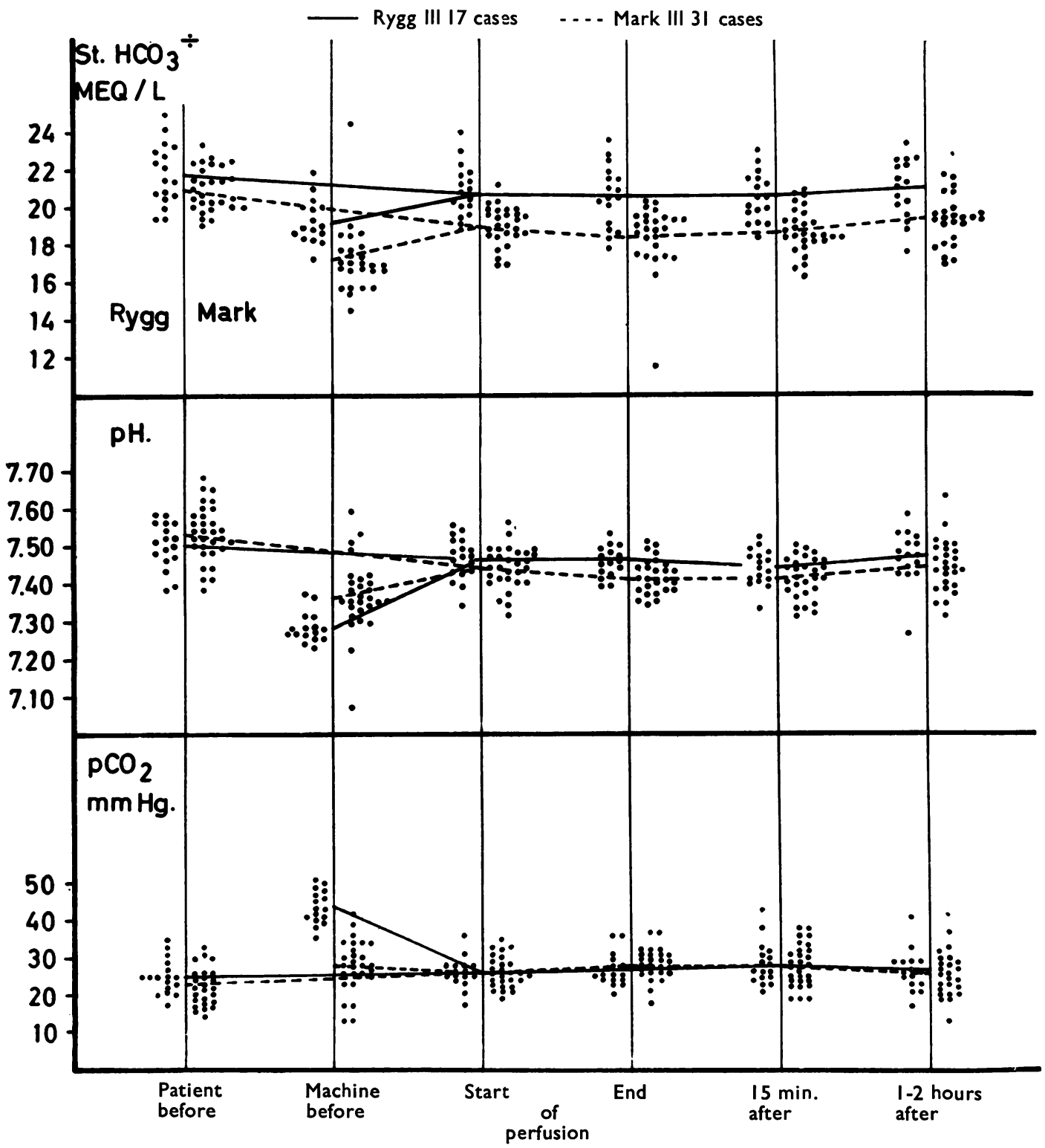

Fig. 4.-Group 1: Values for standard-bicarbonate, $p \mathrm{H}$ and $\mathrm{pCO}_{2}$ before, during, and after perfusion of 48 cases of atrial septal defect. The mean values are given as lines. 
1937). The mean relation thus found was $78 \%$ of the expected uptake for the Rygg-Kyvsgaard III series and $72 \%$ for the mark III series.

ACID-BaSe Balance.-To determine the acid-base balance of the blood, the arterial $p \mathrm{H}, \mathrm{pCO}_{2}$, and standard bicarbonate were measured.

For group 1 these values have been plotted in a scattergram (Fig. 4), in which the mean values have been given as lines. It appears from the scattergram that the three values are more or less even in the blood of the patients before the perfusion, whereas in the donor blood a variance is seen between the two series, as the standard bicarbonate values are on an average about $2 \mathrm{mEq}$./1. lower in the mark III series than in the Rygg-Kyvsgaard III series.

$\mathrm{pCO}_{2}$ in the donor blood of the mark III series shows a considerable dispersal, with the greater part of the analyses lying between 25 and $35 \mathrm{~mm}$. $\mathrm{Hg}$ whereas the corresponding values in the RyggKyvsgaard III series lie between 40 and $50 \mathrm{~mm}$. $\mathrm{Hg}$. This relationship is reflected in the values for $p \mathrm{H}$, as the lower $\mathrm{pCO}_{2}$ in the donor blood of the mark III series before the perfusion raises the $p \mathrm{H}$ to a mean of 7.36 , whereas $p \mathrm{H}$ in the donor blood of the Rygg-Kyvsgaard III series averages 7.28.

During the perfusions the $\mathrm{pCO}_{2}$ values were practically the same in the two series, whereas the influence of the donor blood manifests itself in the values for standard bicarbonate, from which the variance between the donor blood of the two series can be read throughout the perfusion. Similarly, the values for $p \mathbf{H}$ are found to be a trifle lower in the mark III series than in the RyggKyvsgaard III series.

Fig. 5 is a balance scattergram showing the changes in standard bicarbonate, $\mathrm{pH}$, and $\mathrm{pCO}_{2}$ from the beginning to the end of the perfusions in group 1 . A slight rise in $\mathrm{pCO}_{2}$ and a corresponding drop in $p \mathrm{H}$ in the mark III series is seen, but otherwise no changes of any importance are found.

The cases in group 2, the more complicated malformations, do not lend themselves to an unqualified comparison, and cannot be recorded graphically in the same way as those in group 1, since the dissimilarity of the malformations, the varying duration of the perfusions, and the heterogeneity of the operations render it impossible to make a complete picture. We have therefore drawn a number of individual curves of the changes in standard bicarbonate during the perfusions in group 2 (Fig. 6a and b), as we have considered this value the most important indicator of the quality of the perfusions. On these curves,

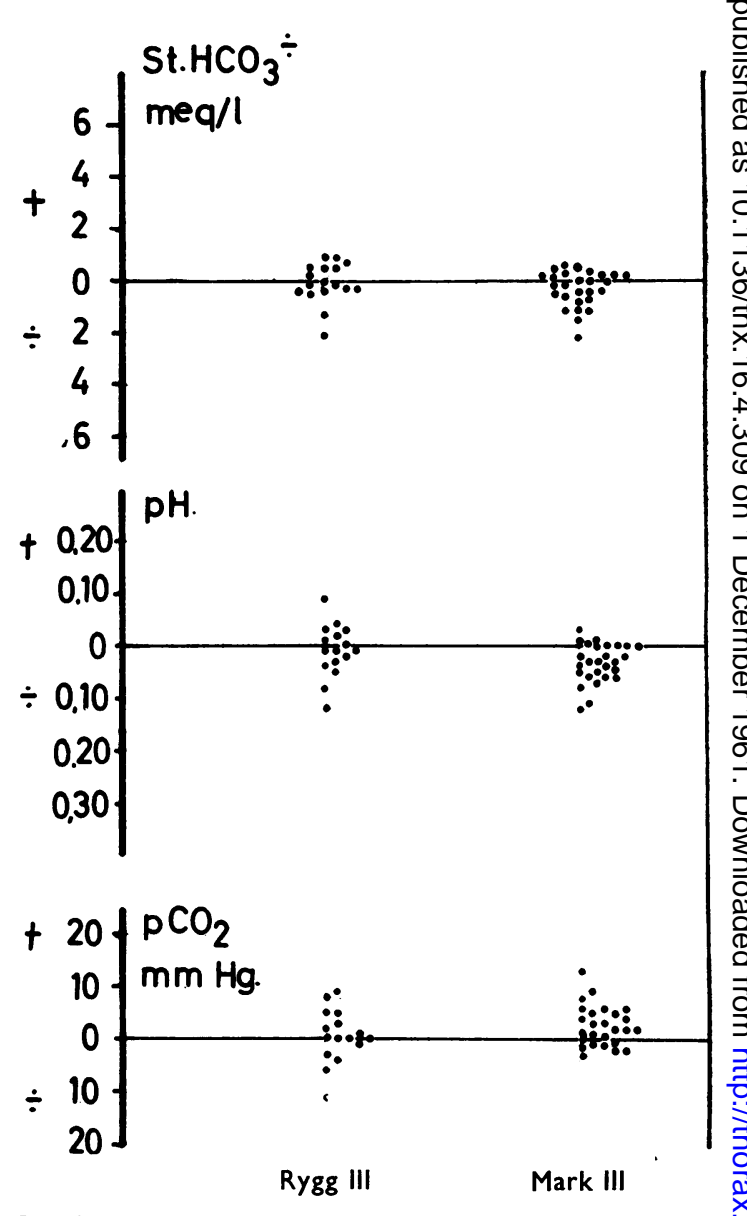

FIG. 5.-Group 1: Balance scattergram showing changes in the values for standard bicarbonate, $p \mathrm{H}$, and $\mathrm{pCO}_{2}$ during perfusions.

for which we have thought it of essential importance to indicate the duration of the 은 individual perfusions, regard for clarity has $D$ rendered it impossible to sketch in the further course, which, however, in this heterogenous group is of no importance for the evaluation of $O$ individual perfusions.

In the mark III series, seven cases from this group have been excluded, as we have found them not suitable for comparison. They include three cases of extracorporeal circulation combined with hypothermia, one of atrial septal defect in which a haemorrhage of 30 litres occurred during operation, the above-mentioned case of massive air embolism, one case in which, owing to unsuitable venous catheters, it became necessary to perfuse at a very low rate ( 1.3 litres/sq.m./min.), and finally a case from which the last blood sample 


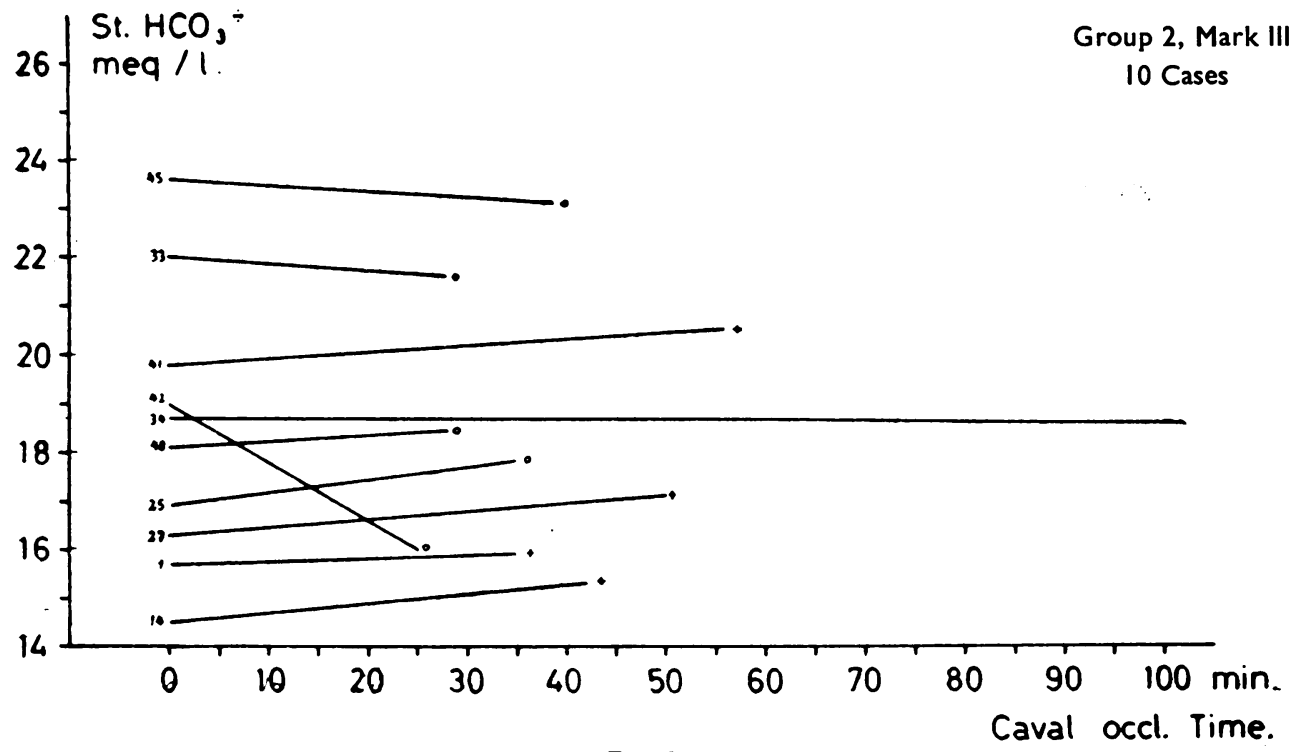

FIG. $6 a$

Group 2, Rygg III

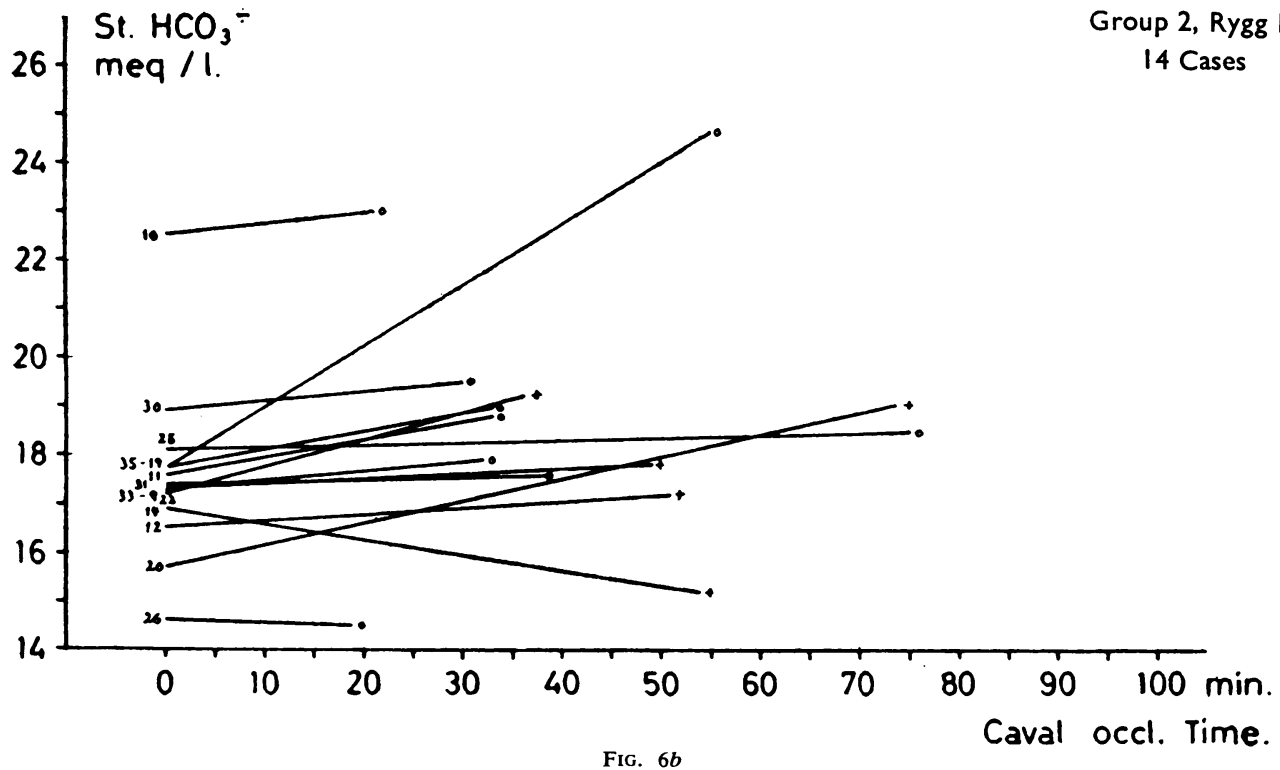

FIG. $6 a$ and $6 b$.-Group 2: Course of 10 perfusions with the mark III pump oxygenator and 14 perfusions with the RyggKyvsgaard III pump oxygenator, shown by individual curves of the changes in standard bicarbonate during the perfusions. The fatal cases are indicated by crosses, the survivors by circles.

was drawn after the discontinuance of the perfusion and after cardiac massage. In the RyggKyvsgaard III series no cases were excluded.

For the rest, the results appear from the curves. With the exception of one case in each of the two series (M42 and R14), the curves from all the perfusions show a satisfactory course. It appears, moreover, that on the whole the surviving patients within both series show higher standard bicarbonate values than do the fatal cases.

Case M42 was a 5-year-old girl, who was operated on for what was considered an atrial septal defect. Subsequent examinations have proved that she must also have suffered from a ventricular septal defect. A 
flow at $2,900 \mathrm{ml}$./sq.m./min. was applied, but it was impossible to maintain an arterial pressure of more than $60 \mathrm{~mm}$. $\mathrm{Hg}$, and the venous pressure was raised (25 mm. $\mathrm{Hg}$ ). The temperature was kept between $37.5^{\circ}$ and $38^{\circ}$. The patient survived the operation but has shown no improvement.

Case R14 was a $1 \frac{1}{2}$-year-old girl, who was perfused with a flow of $2,300 \mathrm{ml}$./sq.m./min. The blood pressure was satisfactory as were the other circumstances of the perfusion, and the temperature was normal. No explanation is available for the heavy drop in standard bicarbonate, except that the arterial flow may scarcely have been sufficient for this patient. The diagnosis was total anomalous pulmonary drainage, and it was impossible to make a satisfactory surgical correction. The patient died during the first post-operative 24 hours.

HaEmolysis. - The haemolysis, expressed as mg. \% free haemoglobin in serum, was examined at the end of the perfusions. The mean values for both groups collectively were in the mark III series $35 \mathrm{mg}$ \% and in the Rygg-Kyvsgaard III series $58 \mathrm{mg} . \%$. In the Rygg-Kyvsgaard III series, in which a varying number of suctions was applied, no correlation was found between the number of intracardiac suctions and the degree of haemolysis.

Blood Cell Counts.-Before, during, and after each perfusion a platelet count and a leucocyte count (including differential count) was taken. Fig. 7 shows the result of the platelet count for

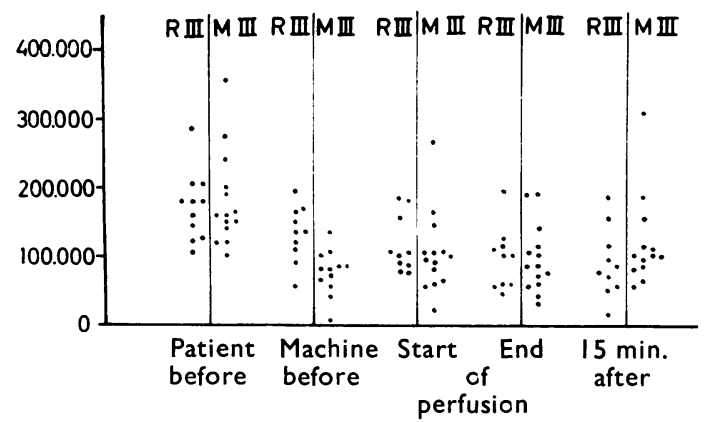

FIG. 7.--Thrombocyte counts before, during, and after the perfusion.

groups 1 and 2 collectively. Apart from somewhat lower values in the donor blood of the mark III series, no evident variance is found between the two materials.

Fig. 8 shows the changes for both groups collectively in the total number of leucocytes before, during, and after the perfusion. Here, too, the values in the donor blood are lower in the mark III series than in the Rygg-Kyvsgaard III series. At the change-over to perfusion, the values in the Rygg-Kyvsgaard III series correspond to a mixture of donor blood and blood from the patients, whereas in the mark III series the

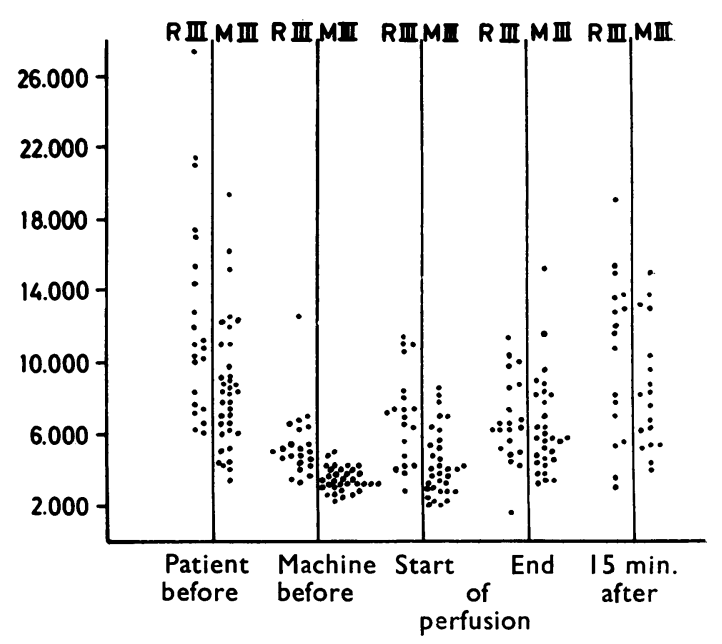

FIG. 8.-Leucocyte counts before, during, and after the perfusion.

values were not raised to this level until at the end of the perfusion. Only 15 minutes after the perfusion a commencing upwards dispersal of the number of leucocytes is seen.

The results of the differential count are seen in Fig. 9. The total heights of the columns indicate the mean of the total number of leucocytes at the time when the test was made (cf. Fig. 8). The various hatchings show the mean of the various groups of cells on the basis of 22 registrations in each series, except for the last set of samples, in

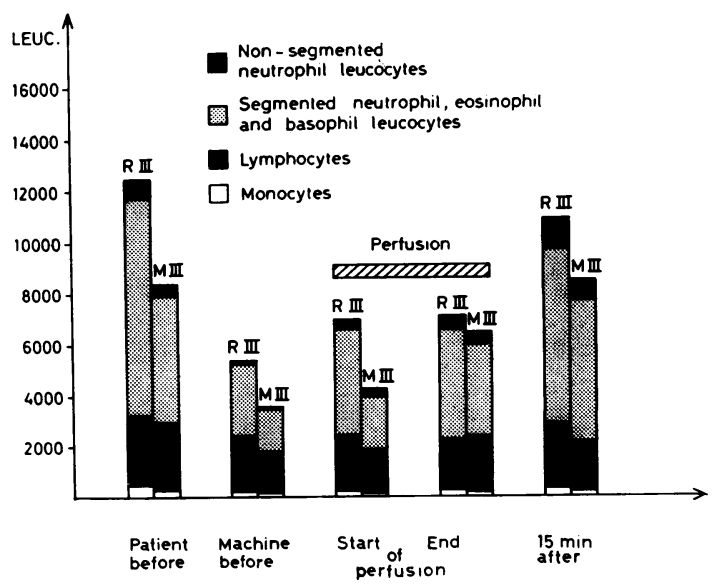

FIG. 9.-Differential leucocyte counts before, during, and after the perfusion.

which only 13 registrations were made in the RyggKyvsgaard III series and nine in the mark III series. The content of granulocytes is about $60 \%$ lower in the donor blood than in the blood of the patients before the perfusion. At the beginning of the perfusion, the number of granulocytes in 
the Rygg-Kyvsgaard III series corresponds to a simple mixture of blood from patients and donors, whereas the number of these cells in the mark III series is lower in this test than might have been expected from a simple mixture. During the perfusion, however, the granulocytes in the mark III series increase to the same number as in the RyggKyvsgaard III series.

There is practically no change in the lymphocytes before, during, and after the perfusion, and the changes in the number of leucocytes during the perfusion may thus be ascribed almost exclusively to the condition of the granulocytes.

Serum Protein.-Fig. 10 shows the changes in the values for serum protein. The analysis shows

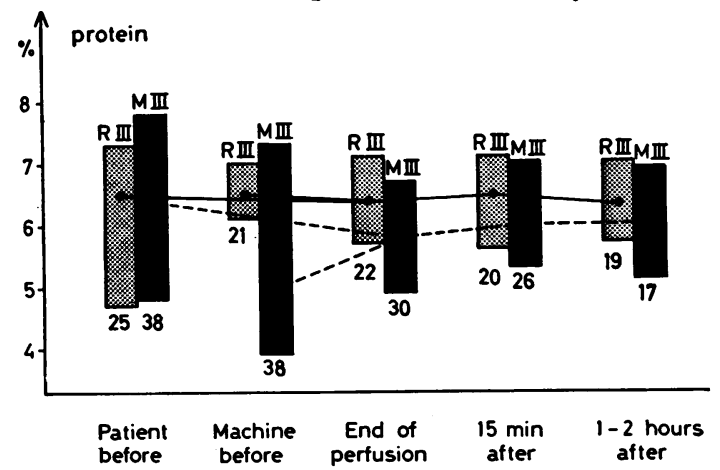

FIG. 10.-Serum protein values before, during, and after the perfusion. The columns indicate the dispersion of the values; the means are indicated by dots. The number of registrations appears from the figures underneath the columns.

a lower value in the donor blood of the mark III series than in the donor blood of the RyggKyvsgaard III series, and this divergence also asserts itself in the values after the perfusion.

HAEMOGLOBIN.-In Fig. 11 are seen the changes in the haemoglobin values. Owing to mixing with saline water during the filming procedure, the donor blood is diluted in the mark III apparatus, manifesting itself in the fact that the average haemoglobin value in the donor blood of the mark III series is $11.8 \mathrm{~g} . \%$, whereas the corresponding value in the Rygg-Kvysgaard III series is $13.9 \mathrm{~g}$. \%. For the rest, conditions corresponding to those mentioned under serum protein are seen.

SERUM Electrolytes.-Values for potassium, sodium, and chloride were registered in the blood of the patients before and after the perfusion and in the donor blood. It appears from Fig. 12 that there are only small changes in these values for blood from the patients before and after the perfusion, whereas there is a small variance in respect of potassium and chloride between the donor bloods of the two series.

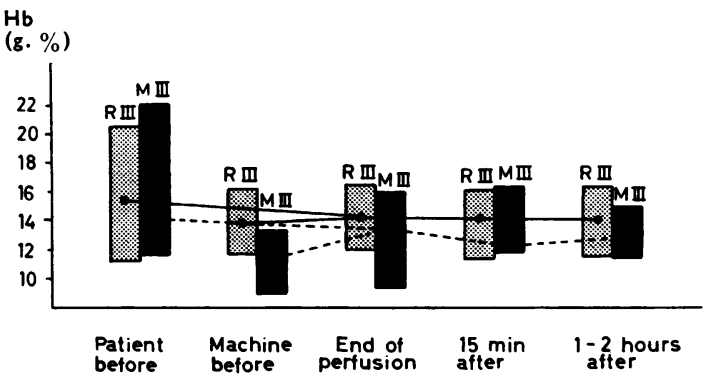

FIG. 11.-Haemoglobin values from all the cases before, during, and after the perfusion. The columns indicate the range of the values; the means are indicated by dots.

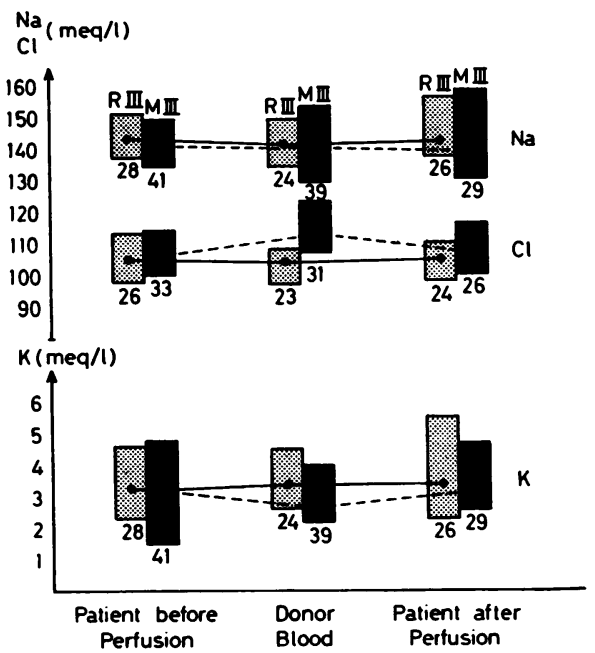

FIG. 12.-Serum electrolyte values before and after the perfusion. The columns indicate the range of the values; the means are indicated by dots. The number of registrations appears from the figures underneath the columns.

\section{Discussion}

We have felt justified in submitting this material for comparison of perfusions made with two different types of pump oxygenators, because both the experimental and the clinical work with extracorporeal circulation with the two types of apparatus have been carried out in parallel series according to the same principles. The perfusions were conducted by the now generally accepted technique, the efficacy of which has also been confirmed by our earlier investigations, our target being an effective flow at 2.4 litres $/ \mathrm{sq} . \mathrm{m} . / \mathrm{min}$. with free venous drainage (Engell, 1957). It has previously been shown (Rygg, Saurbrey, Hasner, Thue Poulsen, and Arnfred, 1961) that among other things a sufficient perfusion is characterized by unchanged or increasing values for standard bicarbonate during the perfusion. An acidosis during a perfusion at which a sufficient oxygena- 
tion and an adequate arterial flow has been maintained is not caused by the perfusion itself but by the admixture of donor blood.

Apart from the principle of oxygenation, the difference between the two pump oxygenators is characterized by a considerably lower priming volume in the Rygg-Kyvsgaard III apparatus, which, moreover, is dependent upon the size of the patient, as various sizes of oxygenators are being used. Apart from the use of a five-screen oxygenator for perfusion of small infants, the mark III apparatus has a fixed and, especially when a heat exchanger is applied, a very considerable priming volume, which causes perfusions with this type, especially of young individuals, to involve a heavy admixture of donor blood and a consequential acidosis. On the other hand, the big priming volume means, other things being equal, a reduced number of passages through the apparatus and a consequential reduced traumatic effect on the blood.

The special technique used for filming the oxygenator of the mark III apparatus involves an admixture of saline to the donor blood and consequently reduced haemoglobin and bicarbonate concentrations, and also the relative content of electrolytes is changed. Thus, in estimating the traumatic effect on the blood, these two facts must be taken into consideration, as must also the amount of blood transfused during the perfusion, the patient's own blood volume, and the minute volume at which the perfusion has been performed. Moreover, the traumatic effect on the blood depends upon the construction of the pump, the materials with which the blood comes into contact, the type of suction, and the vacuum used in the suctions.

As mentioned above, our type of case permits only in group 1 a closer comparison of the perfusions, but even here it may be difficult to draw any definite conclusions, as, for instance, at perfusions with the mark III apparatus a fall in arterial pressure has been observed during the first minutes of the perfusion immediately after caval occlusion, and at some perfusions the venous pressure was raised due to unsuitable caval catheters.

Even though the method of calculation mentioned under oxygen uptake is subject to several possibilities of error, we have nevertheless found ourselves justified in using it for a comparison, pointing out, however, that possible errors or inaccuracies in calculating the temperature correction, either upwards or downwards, will assert themselves more heavily in the mark III series, as the average temperature is lower here than in the Rygg-Kyvsgaard series.

The oxygen uptake established corresponds excellently to the investigations published by Shackman, Graber, and Melrose (1953) and by Starr (1959), who have demonstrated that during anaesthesia and extracorporeal circulation the basal metabolism is reduced to a figure of this magnitude. The present variance between $72 \%$ and $78 \%$ respectively has appeared not to be significant. From a survey of the other results of our investigations it appears that the dilution of the donor blood in the mark III apparatus has had a not unimportant influence on the divergencies found between the two series. This circumstance makes itself especially felt in the values for standard bicarbonate, for which the variance remains stable throughout the perfusion and during the following period.

It is a matter of course that the changes in the value for standard bicarbonate of the blood are less in evidence during the brief perfusions in group 1 than in more protracted operations, but we are nevertheless of the opinion that the two sets of patients within this group show with sufficient distinctness that no metabolic acidosis occurs as a result of the perfusion, so that the acidosis found was due exclusively to admixture of donor blood. This is particularly obvious from the balance scattergram, in which for both groups most dots lie around zero (Rygg, Jørgensen, Lauersen, Astrup, and Therkelsen, 1959).

In our opinion the lower value for standard bicarbonate in the mark III series has been of no importance either for the perfusion or for the postoperative course.

In the case of group 2, it is, as mentioned before, impossible to make a direct comparison of the perfusions on the basis of numerical values, partly because the original values are very heterogeneous owing to the incongruous patient material, and partly because the duration of the perfusions varies very much-from 19 to 102 minutes. It is possible, however, from the individual curves shown to form a picture of the quality of the perfusions within group 2.

Only one perfusion in each series shows a drop of any importance in the standard bicarbonate level, while all other perfusions within both series have a satisfactory course, although for the higher original values in the mark III series a slight fall during the perfusion must be recorded.

No importance can be attached to the circumstance that the survivors on an average show higher standard bicarbonate values than do the 
fatal cases, as the original values for these cases are also higher. It must only be taken to mean that cases with higher values for standard bicarbonate, and consequently with better circulatory conditions, will show a higher survival rate than cases with a metabolic acidosis caused by circulatory failure.

The curves of group 2 justify the conclusion that protracted perfusions may be satisfactorily performed with both pump oxygenators, and furthermore confirm the fact that even after a protracted perfusion the extracorporeal circulation does not in itself result in metabolic acidosis, provided a sufficient flow is maintained. It should be emphasized that in the post-operative course no clinical differences have been observed between the two series.

From the curves of the sodium, chloride, and potassium values it appears that there are only very slight changes in these values, and that the dispersal is only moderate. The lower value for potassium in the donor blood of the mark IIII series may be explained as a consequence of the dilution, whereas the higher value for chloride in this test presumably may be ascribed to the sterilizing procedure (Warexin $\mathbf{R}$ ). The curves of the various cell counts show practically uniform relationships for the two types of apparatus. The conditions of the granulocytes correspond exactly to what has previously been found in donor blood (Bagdassarow and Guljajew, 1958) and the perfusion in itself causes no essential change in the conditions of the leucocytes, which we have also confirmed by determining, concurrently with the tests made of the blood used in the perfusion, the changes in the donor blood kept as a reserve.

\section{CONCLUSION}

From these two groups of cases perfused by a screen oxygenator of the type mark III and a bubble oxygenator of the type Rygg-Kyvsgaard III we have demonstrated that even protracted perfusions may be performed satisfactorily with both types of pump oxygenators, and that the differences found between the various values for acidbase balance, oxygen uptake, and traumatic effect on the blood are either unimportant or insignificant.

Excepting for haemolysis, which in the RyggKyvsgaard III series lies a little higher than in the mark III series, it is, however, worth while emphasizing that in all results at which differences are found between the two series the results are somewhat better in the Rygg-Kyvsgaard III material than in the mark III material.

Since, moreover, the Rygg-Kyvsgaard III apparatus has a lower priming volume and is much easier to operate than the mark III apparatus, and also demands considerably less preparation for the perfusions, we prefer the Rygg-Kyvsgaard III pump oxygenator to the mark III apparatus.

Supported by grants from the Danish State Research Foundation.

\section{REFERENCES}

Andersen, O. Siggaard, Engel, K., Jørgensen, K., and Astrup, P. (1960). Scand. J. clin. Lab. Invest., 12, 172.

Bagdassarow, A. A., and Guljajew, A. W. (ed.) (1958). Bluttransfusion, p. 152. Verlag Volk und Gesundheit, Berlin.

Boothby, W. M., and Sandiford, I. (1929). Amer. J. Physiol., 90, 290. Christensen, K., and Helweg-Mikkelsen, V. (1959). Arch. Pharm. Chemi., 66, 53.

Du Bois, E. F. (1921). J. Amer. med. Ass., 77, 352.

Engell, H. C. (1957). Acta chir. scand., 112, 429.

Rygg, I., Arnfred, E., Frederiksen, Th., and Poulsen, Thue (1961). Ibid., 122, 243.

Gammelgaard, P. A., Husfeldt, E., and Therkelsen, F. (1957). Ibid., $112,439$.

Gerbode, F., Osborn, J. J., Melrose, D. G., Perkins, H. A., Norman, A., and Baer, D. M. (1958). Lancet, 2, 284.

Gibbon, J. H., Jr. (1953). In Recent Advances in Cardiovascular Physiology and Surgery, pp. 107-113. Minnesota Heart Association. University of Minnesota, Minneapolis.

Hansen, A. Tybjoerg (1949). Acta physiol. scand., 19, Suppl. 68.

Husfeldt, E., Engell, H. C., and Arnfred, E. (1961). Presented at the 27th All-Russian Surgical Congress, Moscow, May, 1:60. - Juhl, O., Rosen, J., Sandøe, E., and Arnfred, E. (1959). Acta chir. scand., Suppl. 245, p. 269.

Lewis, R. C., Kinsman, G. M., and Iliff, A. (1937). Amer. J. Dis. Child., 53, 348.

Maloney, J. V., Jr., Longmire, W. P., Jr., Schmutzer, K. J., Marable, S. A., Raschke, E., Watanabe, Y., Lobpreis, E. L., and Arzouman, J. E. (1958). Surg. Gynec. Obstet., 107, 577.

Rygg, I. H. (1958). In Allen, J. G. (ed.), Extracorporeal Circulation, pp. 39-40, 108-110. Thomas, Springfield, Illinois.

- Engell, H. C., and Kyvsgaard, E. (1956). Dan. med. Bull., 3, 200.

- Jørgensen, K., Lauersen, T., Astrup, P., and Therkelsen, F. (1959). Paper presented at the 3rd World Congress of Cardio logy, Brussels, 1958. Abstracts of Communications, p. 505. and Kyvsgaard, E. (1957). Acta chir. scand., 112, 433.

(1958). Minerva chir. (Torino), 13, 1402.

Saurbrey, J. S., Hasner, E., Poulsen, Thue, and Arnfred, I. (1961). Experimentelle undersogelser over optimalt flow ved. extracorporal circulation med Rygg-Kyvsgaard hjerte-lunge maskine. Presented at the Scandinavian Congress of Thoracic Surgery, Oslo, 1959. (To be published.)

Shackman, R., Graber, I. G., and Melrose, D. G. (1953). Clin. Sci., $12,307$.

Starr, A. (1959). J. thorac. cardiovasc. Surg., 38, 46.

Therkelsen, F., Poulsen, Thue, Rosen, J., and Rygg, I. H. (1961). Acta chir. scand., 122, 252. 